\title{
Prevalence of SARS-CoV-2 infection in Italian pediatric population: a regional seroepidemiological study
}

Manola Comar ${ }^{1,2}$, Simone Benvenuto ${ }^{2 *}$ D, Marzia Lazzerini ${ }^{1}$, Giorgio Fedele $^{3}$, Egidio Barbi $^{1,2}$, Alessandro Amaddeo $^{1}$, Francesco Maria Risso ${ }^{1}$, Tamara Strajn ${ }^{1}$, Paola Di Rocco ${ }^{1}$, Paola Stefanelli and Giovanni Rezza ${ }^{3}$

\begin{abstract}
Background: Data on the effective burden of the SARS-CoV-2 pandemic in pediatric population are very limited, mostly because of the higher rate of asymptomatic or paucisymptomatic cases among children. Updated data on COVID-19 prevalence are needed for their relevance in public health and for infection control policies. In this singlecentre cross-sectional study we aimed to assess prevalence of SARS-CoV-2 infection through IgG antibodies detection in an Italian pediatric cohort.

Methods: The study was conducted in January 2021 among both inpatients and outpatients referring to Research Institute for Maternal and Child Health "Burlo Garofolo" in Trieste, Friuli Venezia-Giulia, Italy, who needed for blood test for any reason. Collected samples were sent to Italian National Institute of Health for analysis through chemiluminescent immunoassay (CLIA).

Results: One hundred sixty-nine patients were included in the study, with a median age of $10.5 \pm 4.1$ years, an equal distribution for sex (49.7\% female patients), and a 55.6\% prevalence of comorbidities. Prevalence of anti-SARSCoV-2 trimeric Spike protein IgG antibodies was 9.5\% $(n=16)$, with a medium titre of $482.3 \pm 387.1 \mathrm{BAU} / \mathrm{mL}$. Having an infected cohabitant strongly correlated with lgG positivity (OR 23.83, 95\% Cl 7.19-78.98, $p<0.0001$ ), while a cohabitant healthcare worker wasn't associated with a higher risk (OR 1.53, 95\% Cl 0.4-5.86, p 0.46). All of the 5 patients who had previously tested positive to a nasopharyngeal swab belonged to the lgG positive group, with a 3-month interval from the infection at most.

Conclusion: We assessed a 9.5\% SARS-CoV-2 seroprevalence in a pediatric cohort from Friuli Venezia-Giulia region in January 2021, showing a substantial increase after the second peak of the pandemic occurred starting from October 2020, compared to 1\% prevalence observed by National Institute of Statistics (ISTAT) in July 2020.
\end{abstract}

Keywords: Seroprevalence, SARS-CoV-2, IgG antibodies, Pediatric

\footnotetext{
* Correspondence: simone.benvenuto2@icloud.com

${ }^{2}$ University of Trieste, Trieste, Italy

Full list of author information is available at the end of the article
}

(c) The Author(s). 2021 Open Access This article is licensed under a Creative Commons Attribution 4.0 International License, which permits use, sharing, adaptation, distribution and reproduction in any medium or format, as long as you give appropriate credit to the original author(s) and the source, provide a link to the Creative Commons licence, and indicate if changes were made. The images or other third party material in this article are included in the article's Creative Commons licence, unless indicated otherwise in a credit line to the material. If material is not included in the article's Creative Commons licence and your intended use is not permitted by statutory regulation or exceeds the permitted use, you will need to obtain permission directly from the copyright holder. To view a copy of this licence, visit http://creativecommons.org/licenses/by/4.0/ The Creative Commons Public Domain Dedication waiver (http://creativecommons.org/publicdomain/zero/1.0/) applies to the data made available in this article, unless otherwise stated in a credit line to the data. 


\section{Background}

At the end of December 2019, a severe acute respiratory syndrome caused by a coronavirus 2 (SARS-CoV-2) emerged in Wuhan (Hubei, China) [1], rapidly spreading worldwide thereafter. On March 11th 2020 WHO assessed the outbreak as a pandemic. Italy was the first European country to be hit by the pandemic [2], being for weeks the second in the world, after China, for number of identified cases. As of March 2021, 3 million cases have been confirmed in Italy, with about 100.000 deaths (https://www.epicentro.iss.it/coronavirus/sars-cov-2sorveglianza-dati).

Despite the high number of infected people, data on the effective burden of the pandemic in pediatric population are very limited, mostly because of the higher rate of asymptomatic or paucisymptomatic cases among children. Given the rapid evolution of the pandemic during winter season, updated data on pediatric COVID-19 prevalence are needed for their relevance in public health and in particular for infection control policies.

Although its role in COVID-19 diagnosis is still poorly defined, especially among children, detection of antiSARS-CoV-2 IgG antibodies represents a useful method to assess epidemiological information in the general population. The aim of this single-centre cross-sectional study was to assess prevalence of SARS-CoV-2 infection through IgG antibodies detection in an Italian pediatric cohort.

\section{Methods}

The study was conducted in January 2021 among children who accessed the Research Institute for Maternal and Child Health "Burlo Garofolo" in Trieste, Friuli Venezia-Giulia, Italy. Both inpatient and outpatients referring to pediatric wards, day hospital, and emergency department were included, based on two inclusion criteria: age < 18 years and need for blood test for any reason. Refusal to participate to the study, risk factors for ongoing SARS-CoV-2 infection (typical symptoms, recent positive nasopharyngeal swab, contact with confirmed or suspected cases, travelling abroad), and/or immunodeficiency, either primitive or secondary, were considered as exclusion criteria. Drug-induced immune suppression was defined for patient receiving chemotherapy, rituximab, immune globulins, and/or glucocorticoids such as methylprednisolone $1 \mathrm{mg} / \mathrm{Kg}$ or equivalent for at least 14 days. Medical staff obtained informed consent from parents, who were asked to fill an anamnestic form with relevant clinical and epidemiological data regarding their children. Specific test tubes were collected at the same time of the planned blood samples, then anonymized and sent to the Italian National Institute of Health for analysis. AntiSARS-CoV-2 trimeric Spike protein IgG antibodies detection was performed through chemiluminescent immunoassay (CLIA) (Diasorin, Italy). Results are expressed as absolute values and percentage; $p$ values were assessed using Fisher's test.

\section{Results}

Between January 5th and 31st 2021, a total number of 198 samples was collected. Among these, 29 samples were excluded, mostly because of the simultaneous presence of suspected for COVID-19 symptoms or because age exclusion criterion was met (Fig. 1). Characteristics of the 169 remaining patients are shown in Table 1. Median age was $10.5 \pm 4.1$ years; all age intervals were well represented in the cohort, with children ranging from 12 to 17 years old being the most prevalent (47.3\%). An equal distribution for sex was observed, with 84 (49.7\%) female patients. Most of the children had Italian citizenship $(154,91 \%)$. Approximately half of them presented at least one comorbidity (94, 55.6\%), with syndromes and/or cerebral palsy being the most prevalent $(22,23.4 \%)$. Children with a cohabitant healthcare worker accounted for $13.4 \%$.

At least one cohabitant infected with SARS-CoV-2 in the last months was reported by 20 patients $(11.8 \%)$. All of these children had been tested with a nasopharyngeal swab and 4 (20\%) had resulted positive. One more patient, without any infected cohabitant, had previously tested positive at the nasopharyngeal swab, globally reaching a $4.1 \%$ prevalence in our cohort.

Among 169 analyzed samples, 16 (9.5\%) children tested positive for anti-SARS-CoV-2 trimeric Spike protein IgG antibodies, with a medium titre of $482.3 \pm 387.1$ BAU/mL. Their characteristics are shown in Table 2. Most of them were outpatients. The median age (10.3 \pm 4.1 years) was comparable with the entire cohort. A slightly higher prevalence was observed in girls (56.3\%). Having a cohabitant healthcare worker (18.7\%) was not associated with a higher risk of antibodies positivity (OR 1.53, 95\% CI 0.4-5.86, p 0.46). Remarkably, 10 patients of this subgroup (62.5\%) reported an infected cohabitant in the last months, so that a statistically significant correlation was observed (OR 23.83, 95\% CI 7.19-78.98, $p<0.0001)$.

Most of the IgG positive patients had received at least one nasopharyngeal swab $(15,93.7 \%)$. All of the 5 children who had previously tested positive at the swab in our cohort belonged to the IgG positive group, accounting for $30 \%$.

\section{Discussion}

To date, this is the first antibody epidemiological study to investigate SARS-CoV-2 infection prevalence in Italian pediatric population after the second peak of the epidemic occurred starting from October 2020. 
January 2021

IRCCS «Burlo Garofolo», Trieste, Italy

198 samples assessed for eligibility:

1. age $<18$ years

2. blood test for any other reason

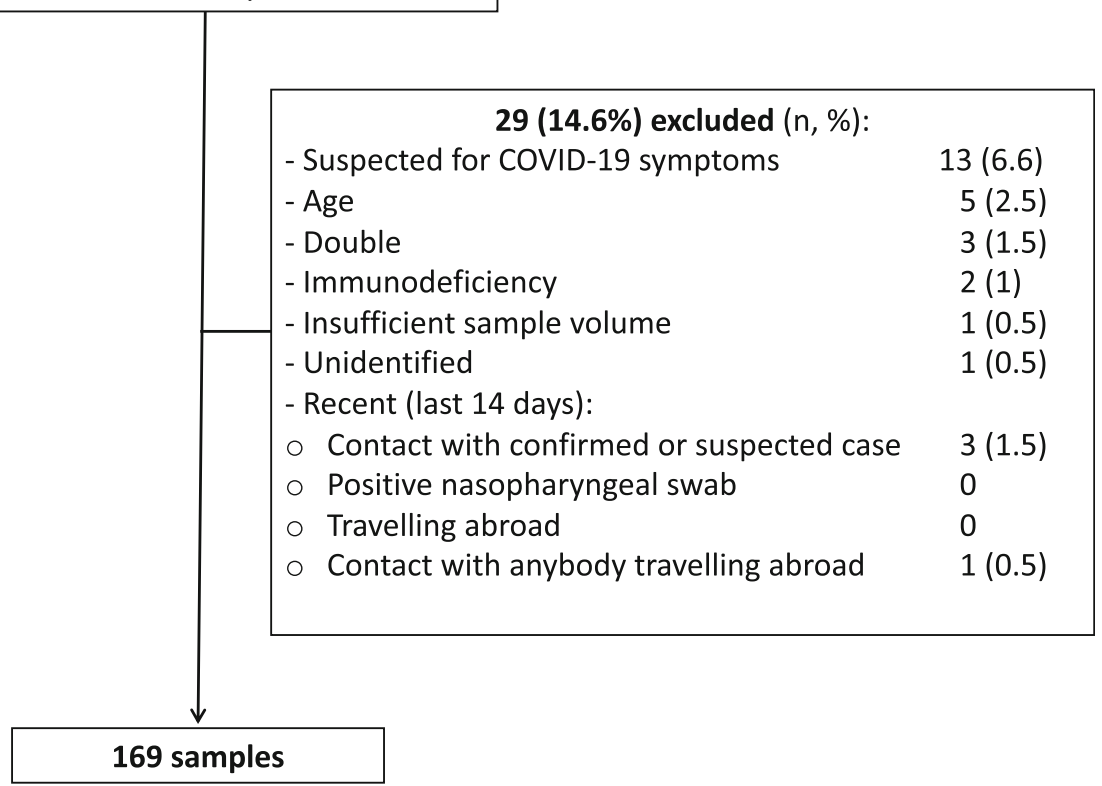

Fig. 1 Flow chart of study population

Data from the Italian case-based surveillance system showed that at the end of the first peak in May 2020 pediatric patients accounted for $1.8 \%$ of total confirmed COVID-19 infections, in a population where $16 \%$ is $<18$ years of age [3]. These data were in accordance with the probable inferior susceptibility to SARS-CoV-2 infection (estimated as approximately half compared to adults) and the higher prevalence of paucisymptomatic (around $80 \%$ in the $10-19$ years group) among pediatric patients [4]. As a matter of fact, both reduced susceptibility and reduced symptoms represent two major obstacles in defining pediatric infection prevalence. This underlines the fundamental role of serology in understanding the real burden of the pandemic. Various antibody tests have been validated so far, reaching their highest sensitivity for detecting previous SARS-CoV-2 infection when used at least 15 days after the onset of potential symptoms [5]. Reported positive percent agreement (PPA) of our test, in particular, was $98.7 \%$ (95\% CI 94.5-99.6\%).

A few studies have evaluated SARS-CoV-2 seroprevalence in adult Italian cohorts. As an example, Vena et al. [6] estimated a medium 11\% IgG and/or IgM positivity in a large population from five administrative departments of Liguria and Lombardia regions, which were among the hardest hit by the pandemic, in April 2020. Citizen above
10 years of age from the Autonomous Province of Trento, which carried the highest incidence of COVID-19 cases, were studied in May 2020 with a resulting IgG antibodies prevalence of $23.1 \%$ [7]. Finally, between May and July 2020, the Italian National Institute of Statistics (ISTAT) assessed an overall $2.5 \%$ seroprevalence in a large sample from 2000 Italian municipalities, with data from Friuli Venezia-Giulia region showing a 1\% prevalence (http:// www.salute.gov.it/imgs/C_17_notizie_4998_0_file.pdf). No recent studies have assessed antibody prevalence evolution in the general Italian population, and in the Friuli Venezia-Giulia in particular.

Concerning this region, a reasonable but large esteem of the burden of the infection could be based on latest mortality data, that is almost 3000 deaths so far, which on a medium lethality rate around $1 \%$ [8] indicate approximately 300 thousand infected people over 1.2 million residents so far, with an expected $30 \%$ seroprevalence. As uncertain as this esteem could be, our study reports an at least 3-folds inferior seroprevalence in pediatric population.

Our cohort indirectly demonstrates the low sensitivity of our current surveillance system: among 15 previously infected children receiving a swab at some point in their past, only $30 \%$ had actually been found positive. However, samples from all of the 5 children who had tested 
Table 1 Characteristics of enrolled patients

\begin{tabular}{|c|c|}
\hline Characteristic & $\begin{array}{l}\text { No of patients }(n=169) \\
(\%)\end{array}$ \\
\hline \multicolumn{2}{|l|}{ Department } \\
\hline - Day Hospital & 77 (45.6) \\
\hline - Pediatric Surgery & $36(21.3)$ \\
\hline - Pediatrics & $24(14.2)$ \\
\hline - Gastroenterology & $14(8.3)$ \\
\hline - Blood Drawing Center & $12(7.1)$ \\
\hline - Emergency Department & $6(3.5)$ \\
\hline \multicolumn{2}{|l|}{ Age } \\
\hline - Mean \pm SD & $10.5 \pm 4.1$ \\
\hline$-\leq 5$ & $28(16.6)$ \\
\hline$-6-11$ & $61(36.1)$ \\
\hline$-12-17$ & $80(47.3)$ \\
\hline \multicolumn{2}{|l|}{ Sex } \\
\hline$-M$ & $85(50.3)$ \\
\hline$-F$ & $84(49.7)$ \\
\hline \multicolumn{2}{|l|}{ Citizenship } \\
\hline - Italy & $154(91)$ \\
\hline - Romania & $4(2.4)$ \\
\hline - Serbia & $4(2.4)$ \\
\hline - Albania & $2(1.2)$ \\
\hline - China & $1(0.6)$ \\
\hline - Pakistan & $1(0.6)$ \\
\hline - Spain & $1(0.6)$ \\
\hline - Turkey & $1(0.6)$ \\
\hline- UK & $1(0.6)$ \\
\hline Comorbidities & 94 (55.6) \\
\hline $\begin{array}{l}\text { - Malformation/Syndrome/Cerebral } \\
\text { Palsy }\end{array}$ & $22(23.4)$ \\
\hline - Obesity & $12(12.8)$ \\
\hline - Prematurity & $10(10.6)$ \\
\hline - Respiratory & $10(10.6)$ \\
\hline - Cardiac & $5(5.3)$ \\
\hline - Diabetes & $4(4.3)$ \\
\hline - Other & $31(33)$ \\
\hline Cohabitant healthcare worker & $23(13.6)$ \\
\hline Having an infected cohabitant & $20(11.8)$ \\
\hline - 1 month before & 7 \\
\hline - 2 months before & 5 \\
\hline - 3 months before & 5 \\
\hline - More than 3 months before & 1 \\
\hline - Unspecified & 2 \\
\hline - Tested by nasopharyngeal swab & $20(100)$ \\
\hline - Positive & $4(20)$ \\
\hline
\end{tabular}

Table 1 Characteristics of enrolled patients (Continued)

\begin{tabular}{ll}
\hline Characteristic & $\begin{array}{l}\text { No of patients }(\boldsymbol{n}=\mathbf{1 6 9 )} \\
(\mathbf{\%})\end{array}$ \\
\hline $\begin{array}{l}\text { Nasopharyngeal swab } \\
\text { - Tested }\end{array}$ & $122(72.2)$ \\
- Positive & $5(4.1)$ \\
$\circ 1$ month before & 2 \\
$\circ 2$ months before & 2 \\
$\circ 3$ months before & 1 \\
$\circ$ More than 3 months before & 0 \\
Anti-SARS-CoV-2 Spike Protein IgG Antibodies \\
- Positive & $16(9.5)$ \\
- Negative & $153(90.5)$ \\
\hline
\end{tabular}

positive to a nasopharyngeal swab were actually found positive for SARS-CoV-2 IgG antibodies, with a 3month interval from the infection at most in our cohort. This is in accordance with previous observations in adult cohorts, where SARS-CoV-2 antigen-specific antibodies have been found in $90 \%$ of patients up to 8 months after infection, although not predictive of $\mathrm{T}$ cell memory and with substantial heterogeneity among individuals [9].

As expected, having an infected cohabitant strongly correlates with IgG positivity, confirming an intrafamilial model of transmission, which is helpful in detecting asymptomatic cases or suspecting late manifestations of the infection such as multisystem inflammatory syndrome in children (MIS-C) or the hypothesized persistence of COVID-19 symptoms, the so-called "Long COVID" [10]. Moreover, our observation that 10/20 (50\%) children reporting an infected household resulted IgG positive is in accordance with previous studies on the topic [11].

No correlation was found between IgG positivity and having a cohabitant healthcare worker, suggesting that the expected greater exposure to contagion is not currently reflecting a higher risk of infection.

The two major limitations of this study are that our sample may suffer from a selection bias and not fully represent the general pediatric population, owing to a considerable prevalence of comorbidities, and the limited dimension of our sample.

\section{Conclusions}

In a single-centre prospective study, we assessed a 9.5\% prevalence of anti-SARS-CoV-2 Spike protein IgG antibodies suggesting that children are actually considerably less infected than adults. This result is significantly higher than observed seroprevalence after the first peak of the pandemic in July 2020 by National Institute of Statistic (ISTAT). IgG antibodies were found at a 
Table 2 Characteristics of patients testing positive for antiSARS-CoV-2 Spike protein IgG antibodies

\begin{tabular}{ll}
\hline Antibodies titre & BAU/mL \\
\hline - Mean \pm SD & $482.3 \pm 387.1$ \\
- Median & 387.4 \\
- Interquartile range & $147.3-650.6$ \\
- Max & 1331.2 \\
- Min & 87.9
\end{tabular}

\section{Department}

$\begin{array}{ll}\text { - Day Hospital } & 8(50) \\ \text { - Pediatric Surgery } & 4(25) \\ \text { - Blood Drawing Center } & 2(12.5) \\ \text { - Pediatrics } & 1(6.25) \\ \text { - Gastroenterology } & 1(6.25) \\ \text { - Emergency department } & 0\end{array}$

\section{Age}

- Mean \pm SD

$-\leq 5$

$-6-11$

$-12-17$

Sex

$\begin{array}{ll}-M & 7(43.7) \\ - \text { F } & 9(56.3)\end{array}$

\section{Citizenship}

- Italy
- Albania
Comorbidities
- Malformation/Syndrome/Cerebral Palsy
- Obesity
- Prematurity
- Respiratory
- Diabetes
- Cardiac
- Other

\section{Cohabitant healthcare worker}

- OR, 95\% Cl, p value

\section{Having an infected cohabitant}

- OR, 95\% Cl, $p$ value

- 1 month before

- 2 months before

- 3 months before

- More than 3 months before

- Tested by nasopharyngeal swab

- Positive

$15(93.7)$

1 (6.4)

$12(75)$

$4(33.4)$

$3(25)$

$2(16.7)$

1 (8.3)

$1(8.3)$

0

$3(18.7)$

$1.53,0.4-5.86,0.46$

$10(62.5)$

$23.83,7.19-78.98,<0.0001$

$6(60)$

1 (10)

$3(30)$

0

$10(100)$

$4(40)$

\section{Nasopharyngeal swab}

- Tested
Table 2 Characteristics of patients testing positive for antiSARS-CoV-2 Spike protein IgG antibodies (Continued)

\begin{tabular}{ll}
\hline Antibodies titre & BAU/mL \\
\hline - Positive & $5(30)$ \\
$\circ 1$ month before & $2(40)$ \\
$\circ 2$ months before & $2(40)$ \\
$\circ 3$ months before & $1(20)$ \\
$\circ$ More than 3 months before & 0 \\
\hline
\end{tabular}

maximum 3-months interval from the infection. Having an infected cohabitant is strongly associated with IgG antibodies detection, while cohabitant healthcare workers don't seem to carry a greater risk. These data could be helpful to plan better infection control policies also considering the possible impact of SARS-CoV-2 variant on this group.

\section{Abbreviations}

SARS-CoV-2: Severe Acute Respiratory Syndrome Coronavirus 2; WHO: World Health Organization; COVID-19: Coronavirus Disease 2019;

CLIA: Chemiluminescent Immunoassay; OR: Odds Ratio; Cl: Confidence Interval; PPA: Positive Percent agreement; ISTAT: National Institute of Statistics

\section{Acknowledgements}

The authors would like to thank the study's participants. They also thank Cristina Tumminelli and Martina D'Agostin for the relevant contribution in patient's enrolment, and the entire medical and nursing staff of our Institute involved in the study.

\section{Authors' contributions}

ML, MC, EB and SP conceived the study. SB, AA, FMR, TS and SS collected the patient's data. SB analyzed the data and wrote the first draft of the manuscript. All authors made substantial revision of the manuscript and approved the final version.

\section{Funding}

None of the authors received any honorarium, grant, or other form of payment for this study.

\section{Availability of data and materials}

The datasets generated and/or analyzed during the current study are not publicly available due to individual privacy reasons.

\section{Declarations}

Ethics approval and consent to participate

Obtained by local ethics committee (IRB-Burlo 09/2020 18.11.2020).

\section{Consent for publication}

Obtained by patient's parents.

\section{Competing interests}

The authors declare that they have no competing interests.

\section{Author details}

"Institute for Maternal and Child Health, IRCCS "Burlo Garofolo", Trieste, Italy. ${ }^{2}$ University of Trieste, Trieste, Italy. ${ }^{3}$ Italian National Institute of Health, Rome, Italy. 
Received: 16 March 2021 Accepted: 17 May 2021

Published online: 05 June 2021

\section{References}

1. Li Q, Guan X, Wu P, Wang X, Zhou L, Tong Y, et al. Early transmission dynamics in Wuhan, China, of novel coronavirus-infected pneumonia. N Engl J Med. 2020;382(13):1199-207. https://doi.org/10.1056/NEJMoa2001316.

2. World Health Organization. Coronavirus disease (COVID-2019) situation reports 49. Available at (Accessed on 10th March 2020) https://www.who. int/emergencies/diseases/novel-coronavirus-2019/situation-reports

3. Bellino S, Punzo O, Rota MC, et al. COVID-19 Disease Severity Risk Factors for Pediatric Patients in Italy. Pediatrics. 2020;146(4):e2020009399. https://doi. org/10.1542/peds.2020-009399.

4. Davies NG, Klepac P, Liu Y, et al. Age-dependent effects in the transmission and control of COVID-19 epidemics. Nat Med. 2020 Aug;26(8):1205-11. https://doi.org/10.1038/s41591-020-0962-9.

5. Deeks JJ, Dinnes J, Takwoingi Y, et al. Antibody tests for identification of current and past infection with SARS-CoV-2. Cochrane Database Syst Rev. 2020;6(6):CD013652. https://doi.org/10.1002/14651858.CD013652.

6. Vena A, Berruti M, Adessi A, et al. Prevalence of Antibodies to SARS-CoV-2 in Italian Adults and Associated Risk Factors. J Clin Med. 2020;9(9):2780. Published 2020 Aug 27. https://doi.org/10.3390/jcm9092780.

7. Stefanelli P, Bella A, Fedele G, et al. Prevalence of SARS-CoV-2 lgG antibodies in an area of northeastern Italy with a high incidence of COVID19 cases: a population-based study. Clin Microbiol Infect. 2020;27(4):633.e1. https://doi.org/10.1016/..cmi.2020.11.013

8. WHO. Estimating mortality from COVID-19: Scientific brief, 2020. https:// www.who.int/publications/i/item/WHO-2019-nCoV-Sci-Brief-Mortality-2020.1

9. Dan JM, Mateus J, Kato Y, et al. Immunological memory to SARS-CoV-2 assessed for up to 8 months after infection. Science. 2021;371(6529): eabf4063. https://doi.org/10.1126/science.abf4063.

10. Buonsenso D, Munblit D, De Rose C, et al. Preliminary evidence on long Covid in children. Acta Paediatr. 2021. https://doi.org/10.1111/apa.15870 Epub ahead of print.

11. Buonsenso D, Valentini P, De Rose C, et al. Seroprevalence of anti-SARSCoV-2 lgG antibodies in children with household exposure to adults with COVID-19: preliminary findings. Pediatr Pulmonol. 2021;56(6):1374-7. https:// doi.org/10.1002/ppul.25280 Epub ahead of print.

\section{Publisher's Note}

Springer Nature remains neutral with regard to jurisdictional claims in published maps and institutional affiliations.

Ready to submit your research? Choose BMC and benefit from:

- fast, convenient online submission

- thorough peer review by experienced researchers in your field

- rapid publication on acceptance

- support for research data, including large and complex data types

- gold Open Access which fosters wider collaboration and increased citations

- maximum visibility for your research: over $100 \mathrm{M}$ website views per year

At BMC, research is always in progress.

Learn more biomedcentral.com/submissions 